\title{
ERRATUM
}

ERRATUM

Corrigendum to Volume 114, Number 7, p 1184-1185

(C) Springer-Verlag 2009

\section{Atlante elementare delle deformità congenite dello scheletro}

\author{
G. Canepa • A. Renieri
}

Piccin Nuova Libraria S.p.A., Padova 2009

ISBN 978-88-299-2001-3

e

\section{Atlante disegnato delle malattie congenite dello scheletro}

\author{
G. Canepa - A. Renieri
}

Piccin Nuova Libraria S.p.A., Padova 2009

ISBN 978-88-299-2002-0

In the article unfortunately one title was missing

The original version of the article can be found at:

http://dx.doi.org/10.1007/s11547-009-0471-x 